\title{
Os sentidos do trabalho do professor e o lugar social do ensino de História
}

\author{
Jorge Luiz da Cunha* \\ Universidade Federal de Santa Maria \\ Lisliane dos Santos Cardôzo** \\ Rede pública estadual do Rio Grande do Sul
}

Resumo Através da identidade narrativa de professores formados no curso de História da Universidade Federal de Santa Maria (UFSM), nosso objetivo, neste artigo, foi pesquisar como a formação inicial tem implicado no trabalho de cada um deles, em suas trajetórias de vida e como cada sujeito interpreta o lugar social do Ensino de História. A identidade narrativa teve destaque por meio da abordagem (auto)biográfica. Entendemos que a ciência histórica pode ter um papel orientador, na contemporaneidade, através da consciência histórica. O Ensino de História só pode ter um papel orientador estando inserido na cultura histórica. $\mathrm{E}$, assim, envolvendo questões morais, éticas, pedagógicas, existenciais, entre outras, é que podemos constituir sentido histórico para orientar a vida e a capacidade de aprender historicamente. O aprendizado histórico não compreende só aprender conteúdos do passado, é um engajamento do sujeito social que se entende pela História, interpretando a História objetiva e subjetivamente.

PALAVRAS-CHAVE: Ensino de História; Trabalho do professor; (Auto) biografia.

Abstract Through the narrative identity of teachers graduated in the History Course at Federal University of Santa Maria (UFSM) we aimed in this article to investigate how their initial education has implied in their work, life trajectory and how each of them construe the history teaching social space. The narrative identity was highlighted by addressing a (auto) biographical approach. It is our understanding that the historical science may play a guiding role in contemporaneity over a historical awareness. The history teaching may only play this guiding role if inserted in the historical culture. Thus, involving moral, ethical, pedagogical, existential, among other issues is the only way we may build a historical sense to guide life and the ability to learn historically. Historical learning does not include only the learning of contents from the past. It is an engagement of the social individual understood by History, interpreting History objectively and subjectively.

KEYWORDS: History teaching; Teacher work; History teaching social space. 


\section{Introdução}

Este artigo tem por objetivo pesquisar, através da identidade narrativa de professores formados no curso de História da Universidade Federal de Santa Maria (UFSM), como a formação inicial tem implicado no trabalho de cada um deles, em suas trajetórias de vida e como cada sujeito interpreta o lugar social do Ensino de História. Partindo desse escopo a identidade narrativa (RICOEUR,1997, 2000, 2006) teve destaque por meio da abordagem (auto)biográfica (DELORY-MOMBERGER, 2008, 2011) (JOSSO, 2002, 2006). Para isso, entrevistamos quatro professores formados no curso de História da UFSM e atuantes no Ensino de História na Educação Básica.

Nosso foco é explorar quais são os sentidos do trabalho dos professores e como interpretam qual é o lugar social do Ensino de História, a partir de suas memórias e narrativas. Entendemos que a ciência histórica pode ter um papel orientador, na contemporaneidade, através da consciência histórica (RÜSEN, 2001, 2007). O Ensino de História só pode ter um papel orientador estando inserido na cultura histórica. E, assim, envolvendo questões morais, éticas, pedagógicas, existenciais, entre outras, é por meio dessa cultura que podemos constituir sentido histórico para orientar a vida e desenvolver a capacidade de aprender historicamente. $\mathrm{O}$ aprendizado histórico não compreende só aprender conteúdos do passado, é um engajamento do sujeito social que se entende pela História, interpretando a História também subjetivamente, e não apenas no campo objetivo.

\section{Narrativas: o trabalho de educar historicamente}

O trabalho do professor de História tem suas idiossincrasias. Lida com questões e conceitos existenciais: o tempo, a memória, o passado, o sujeito social e sua historicidade. $\mathrm{O}$ professor trabalha com esses conceitos em um contexto onde ocorre a presentificação do tempo, onde o antigo é obsoleto e arcaico e, logo, pode ser ignorado e esquecido. Cada dia mais, o trabalho com a História é desafiador. O caráter presenteísta do tempo não desqualifica a importância dos processos educacionais formais do Ensino de História, ao contrário, contrapõe-se a essa lógica e auxilia o aluno a compreender a historicidade da vida social e dele enquanto sujeito social. A História pode ajudar a problematizar o caráter imediatista do mundo contemporâneo, em que tudo são mercadorias e descartáveis, objetivando superar o fatalismo das relações e a naturalização dos processos por meio do estranhamento e da alteridade.

A professora Roselene, quando perguntada sobre como se sente em relação ao seu trabalho, respondeu:

[...] eu amo História e amo muito trabalhar História, a docência em História, dar aula de História me fascina, me encanta, me dá prazer e não só a docência, mas a pesquisa também. Eu não consigo separar uma coisa da outra, não há separação, não tem como você trabalhar a docência sem pesquisa e a pesquisa sem docência [...] as duas pra mim me dão muito prazer, me satisfazem muito. 
E complementa:

\begin{abstract}
Alguns podem ter sentido esse mal estar, eu nunca senti. "Ah, o salário não era bom" [...] É óbvio, o salário não é bom, mas, naquele momento, foi o que eu escolbi. Ninguém me obrigou a fazer concurso e ir trabalhar na rede pública estadual. Quando eu fui trabalhar lá, eu sabia quanto eu ia ganhar, claro que eu queria ganhar mais e lutei muito, fiz muita greve, muita manifestação, muita participação em assembléia pra conseguir um reconhecimento maior e melhor do meu trabalho. Isto é importante, mas isso, o salário não me causava um mal-estar, a indisciplina em sala de aula nunca foi motivo pra me estressar, pra me causar mal-estar. Mal-estar docente, se existe, eu acredito que seja interno, entende? E não tanto externo, os fatores sejam mais internos que externos, você me compreende? (ROSELENE).
\end{abstract}

Roselene explicita que o estudado mal-estar docente1 é algo que ela não conhece como professora. Afirma que, embora em condições precárias, de baixos salários, indisciplina, ela nunca sentiu um mal-estar motivado pelo trabalho. Contra as condições externas, ela lutou, fez greve, manifestações, mas essas questões não lhe causavam mal-estar. Roselene entende que o mal-estar é motivado mais por fatores internos que externos. Semelhante à narrativa de Roselene, o professor Paulo, quando perguntado sobre os sentidos do seu trabalho, narrou que:

[..] eu amo ser professor, eu adoro dar aula, eu adoro aluno, eu dou aula porque eu gosto. A gente reclama de salário, a gente bate o pé [...] nós somos encrenqueiros. Eu amo, eu amo meus alunos, eu adoro os meus alunos, eu adoro dar aula [...] e assim, eles são uns amores, eu vivo, eu gosto do que eu faço. Os meus alunos se encantam quando eu começo a falar. (PAULO).

O professor afirma que, mesmo sendo "encrenqueiro" e "batendo o pé" a respeito do salário baixo e da exploração, ele ama ser professor e ama seus estudantes, os quais, conforme ele, encantam-se no momento em que ele começa a falar. Para ele, gostar do seu trabalho é pressuposto para ser um bom professor:

Porque se tu não tens esse olhar, tu não consegues ser um bom profissional, porque o professor de História que não é engajado, que não é crítico, não é professor de História, pode até ter o canudo. [...] se tu não és engajado naquilo que tu faz [...]Tu ser professor é uma escolba tua [...] tu escolbeu formar historicamente aquele ser, então tu tem que ter comprometimento com ele [...] eu pra mim, em primeiro lugar, é o aluno. (PAULO).

É premissa básica para o professor de História ser engajado e crítico. Se ele não tiver essas duas qualidades, tem só "o canudo", ou seja, formou-se em História, porém não é professor. Na concepção de Paulo, se o sujeito escolheu ser professor, precisa ser comprometido com os estudantes. Para ele, o estudante está em primeiro lugar. Esse engajamento que o professor defende como determinante é carregado por ele como uma característica marcante no seu cotidiano escolar:

Eu trago a questão do respeito às diferenças, a orientaçẫo sexual, a aceitação que eles têm comigo. No momento que eles passam a ter aula comigo, a visão muda. Eles chegam uns comigo e saem outros. Eu pego uns caras assim machistas, que depois, no final do semestre, eles tão me 
abraçando, tão rindo, conversando, professor pra cá, professor pra lá. Essa gurizada que eu trabalho, a partir de sétima, no início, eu sou um bicho estranho, depois eu sou o professor deles.

Esse professor, motivado por sua orientação sexual, afirma que a questão do respeito é temática de suas aulas. Conforme a narrativa, sua postura influi muito no comportamento dos estudantes, que mudam o seu olhar, antes preconceituoso, sobre o homossexualismo. Então, o estranhamento, de um primeiro momento, acaba terminando com aceitação e respeito. Quando perguntado sobre como foi o começo de seu trabalho, o professor Vitor afirmou:

\begin{abstract}
No começo foi um baque muito grande, porque, como eu disse, a gente vem de uma formação grande, longa, mas, quando você chega pela primeira vez numa sala de aula, parece que não tem instrumentalização pra trabalhar com aquele público de fundamental e médio. Porque aquelas mesmas teorias, aquelas mesmas discussões que se faz não se consegue, por uma questão de tempo, por uma questão do próprio nível de entendimento dos alunos, desenvolverem discussões tão profundas da História. O professor [...] não teve tempo ainda de parar pra fazer essas conexóes e tentar transformar isso numa coisa mais palpável pros alunos, uma coisa mais compreensível pra eles. Então, a primeira sensação que eu tive, que eu acho que muitos têm também, é de se sentir realmente desarmado no começo. Você sente como se fosse ter que fazer outro curso pra aprender a como lidar com aquilo ali, porque, no curso mesmo, você não aprende a lidar com a realidade escolar, você não aprende assim, você não vivencia. O estágio é muito curto[...] não aprende o cotidiano de uma escola, o que é toda a prática do professor [... ] eu me senti muito perdido de ter que buscar inclusive materiais, de ter que elaborar coisas, de ter que estudar coisas pra ver como é que seria a melhor forma de trabalhar, buscar informações sobre livros didáticos, coisa que se faz muito pouco na faculdade, quase não se fala sobre livro didático na faculdade. (VITOR).
\end{abstract}

O professor relata que, no começo, sentia-se desarmado, sentia que teria de fazer outro curso pra aprender a lidar com aquela realidade da escola. O sentimento de que estava "perdido" o obrigou a elaborar materiais e a estudar para entender qual seria a melhor forma de trabalhar com os níveis fundamental e médio, o que ele considera que pouco se faz durante a formação inicial.

\title{
O trabalho dos professores: limites e a realização
}

Através do trabalho, ao longo dos processos históricos, foi possível criarmos condições de sobrevivência para a vida humana, suprindo necessidades essenciais e diversas do ser. Disso, não podemos separar o processo educativo, que interferiu diretamente na transformação e manutenção do trabalho. Ferreira (2010) indica que o trabalho "está relacionado teleologicamente ao que é o ser humano, sua capacidade de intervir na natureza e de se constituir cidadão", sendo que ele "estabelece a condição de o mundo humano existir, o emprego reproduz as relações sociais, viabilizando as condições materiais de sobrevivência, mediante a venda da força de trabalho e um salário" (p. 217). 
O trabalho sempre existiu, constituindo o sujeito social e suas condições materiais de vida. $\mathrm{O}$ trabalho media o ser humano e a natureza para o estabelecimento de relações sociais e produtivas, nas várias, historicamente constituídas, organizações sociopolíticas no decorrer da história. O que nos diferencia dos animais é, portanto, o trabalho, pois, segundo Saviani:

[...] diferentemente dos animais, que se adaptam à natureza, os homens têm de adaptar a natureza a si. [...] Ora, o ato de agir sobre a natureza transformando-a em função das necessidades humanas é o que conhecemos com o nome de trabalho. Podemos, pois, dizer que a essência do homem é o trabalho. A essência humana não é, então, dada ao homem; não é uma dádiva divina ou natural; não é algo que precede a existência do homem. Ao contrário, a essência humana é produzida pelos próprios homens. O que o homem é, é-o pelo trabalho. A essência do homem é um feito humano. É um trabalho que se desenvolve, se aprofunda e se complexifica ao longo do tempo: é um processo histórico. (SAVIANI, 2007, p. 154).

Esse processo em que o sujeito trabalha e transforma a natureza, que é essência humana e resultado de movimentos históricos, "será sempre qualificador, propiciando o exercício da criação, da reflexão e da auto realização" (KUENZER, 2004, p. 240). O trabalho, nessa lógica, é humanizador e libertador, além de ter conotação educativa. Entretanto, essa atividade, que é de essencial importância para a humanidade, mudou com o advento do capitalismo e suas determinações objetivas. $\mathrm{O}$ trabalho, vivido a partir da lógica do capital, modificou-se e se configurou um trabalho alienado, alheio à própria vontade do sujeito social, que já não tem mais domínio sequer sobre o seu próprio tempo.

Ao perder o controle de seu tempo, o trabalhador perde também o "controle de suas ações e de seu corpo". O trabalho é estranhado e produz mercadorias. Nessa lógica, o trabalhador minimiza seu potencial criativo e reflexivo, visto que, desumanizado, perde, muitas vezes, o prazer de trabalhar. A finalidade do capitalismo é acumular riqueza por intermédio do trabalho. Contudo, sendo o próprio capital o detentor dos meios de produção e do trabalho, acontece um processo de precarização e desqualificação do sujeito trabalhador, que não tem mais domínio sobre o seu trabalho nem sobre o que produz. Portanto:

O trabalho pode ser concebido de duas maneiras: a partir de suas características mais gerais, que independem do modo de produção de mercadorias e que, portanto, são intrínsecas à sua natureza; ou a partir das formas históricas que vai assumindo, de acordo com o desenvolvimento das forças produtivas, ou seja, com base na forma concreta que assume em um determinado modo de produzir mercadorias. Estas duas concepções não se opõem, e sim guardam uma relação dialética entre si, em que, ao mesmo tempo, se negam e se afirmam, configurando a dupla face do trabalho: qualificador, prazeroso e, simultaneamente, desqualificador, explorador, causador de sofrimento. (KUENZER, 2004, p. 240).

Essa relação, entre o trabalho que humaniza e o que degrada, é dialética, são noções que se complementam e se contradizem no mundo do trabalho capitalista. 
Através dessa relação, passamos a entender os limites da realização profissional por meio do trabalho e, ainda, a demarcar as fronteiras de possibilidades de intervenção do homem na sociedade por meio do trabalho. Quando estamos refletindo sobre essa prática, estamos pensando sobre os sujeitos, já que o trabalho não é uma categoria abstrata, ele é exercido por homens e mulheres. Não há quem não tenha exercido algum tipo de trabalho. Cada trabalhador é um sujeito e, desse modo, produz subjetividades e sentidos sobre o seu trabalho. $\mathrm{O}$ ser humano não perdeu a sua capacidade de pensar, de transformar e de sentir satisfação por intermédio do trabalho. Entretanto, muitas vezes, ele diminui essa característica humanizadora de forma plena, pois a sua consciência, sua capacidade criadora e seu o prazer em relação ao trabalho se encontram limitados pelos determinantes estruturais. Nesse momento, não se entende mais o trabalho como um processo natural, uma vez que ele cede lugar ao que chamamos emprego $^{2}$, o qual se associa ao que muitos chamam de cidadania, ou seja, sujeitos aptos a produzirem e consumirem. O trabalho, assim, está sempre se constituindo e se modificando. Contudo, permanece a sua centralidade. Com o capitalismo, o trabalho se complexificou e assumiu características que negam a condição do sujeito social livre.

Assim, a classe trabalhadora, embora não mais concentrada apenas na indústria, expandiu-se junto com a precarização, a exploração e o lucro. Essa classe trabalhadora não fica restrita ao trabalho manual direto; nela, também estão incluídos os trabalhadores da educação e o seu trabalho intelectual, ou seja, não-material. A educação, assim como o trabalho, é essência dos sujeitos (SAVIANI, 2007, p. 154). A formação do ser humano é um processo educativo e, se o sujeito existe porque produz as condições de existência, através do trabalho, trabalho e educação se identificam. Todavia, o processo social e humano, que é a educação, igualmente foi afetado pelo advento do capitalismo e, dessa maneira, deixou de ser natural, passando a ser visto como um modo de se conseguir a força de trabalho que o mercado exige, com as "competências" necessárias, ou seja, flexível e polivalente. Isso ocorreu de forma mais acentuada quando se institucionalizou a educação no espaço escolar. Os professores, desde então, não foram vistos como trabalhadores. Minimizou-se o potencial emancipatório do sujeito, já que à escola cabe a função de produzir mão de obra sob o controle do estado, que se pauta em padrões gerencialistas com o intuito de produzir "cidadãos" autônomos, colaborativos, competentes, adaptados e pertencentes ao mercado de trabalho. Concluimos que a escola reproduz o modo de produção capitalista, pois é gerida em função das exigências do mundo do trabalho. Para o professor, fica a ideia, socialmente perpetuada, de vocação/ voluntarismo ou fracasso: "[...] a imagem do professor graduado num curso universitário que se dedica ao ensino se move entre alguém que renunciou à ambição econômica em favor de uma vocação social e de quem não soube nem conseguiu encontrar algo melhor" (ENGUITA, 1991, p. 45).

É nesse contexto que o trabalho dos professores acontece. Ele está condenado à proletarização, que apaga o sujeito social, desconsidera sua singularidade e sua subjetividade, criando um trabalhador genérico, sem face, nos moldes do capitalismo. Assim, o professor precisa moldar sua vida, seus horários, seu tempo para produzir mais, com o mínimo de custo para o Estado. A lógica é tão perversa que o professor, vítima do sistema, acaba, muitas vezes, por reproduzi-lo e defendê-lo por não compreender a escola inserida nessa totalidade. Logo, professores enfatizam para os estudan- 
tes que eles estão se preparando para o mercado de trabalho e que, naquele espaço da escola, desenvolverão competências que os façam capazes de ter um emprego. Isso, na verdade, é uma falácia, porque a escola não é a redentora do capitalismo e não pode ser garantia de empregabilidade.

Nesse ínterim, o que é o trabalho do professor?

[...] o trabalho dos professores, pedagógico por excelência, é a produção do conhecimento sua e dos estudantes, em momentos sociais denominados aula e, para tanto, o tempo é fundamental: para conhecer, para se conhecer, para expor saberes, refletir e elaborar linguagens sobre esses saberes, sistematizá-los sob a forma de conhecimento. (FERREIRA, 2010, p. 207).

Quando nos referimos ao trabalho intelectual, a regulação do tempo ocorre por meio da opressão. Pensar não é uma atividade alheia ao todo e reservada a momentos específicos. E, sobretudo, na escola:

[...] o tempo pode ser restritivo. Iludidos pelo mundo capitalista, os professores envidam esforços ímpares para concretizar sua tarefa, subtraindo quaisquer diferenças, excluindo os desiguais e preenchendo infindos relatórios que mostrem, com evidências estatísticas, que o tempo considerado necessário para a produção do conhecimento foi aproveitado e, mesmo assim, o estudante não produziu conhecimento. (FERREIRA, 2010, p. 218, grifo nosso).

Nesse contexto, o professor acaba por se tornar apenas tarefeiro, ou seja, o desejável trabalhador que "faz tudo". As políticas públicas, dentro da razão mercadológica, intensificam o trabalho dos professores. Em função disso, é afetada a capacidade de reflexão dos professores a respeito de sua práxis:

Observa-se também um acúmulo de responsabilidades quanto aos procedimentos do/a professor/a, tornando sua rotina absorvida por tarefas que impedem uma prática refletida, profundamente articulada com a prática social, transformando tais profissionais em práticos que repetem os procedimentos aprendidos na formação inicial, muitas vezes insuficientes para responder às questões colocadas pelo contexto em que atuam, quanto à sua atuação política e pedagógica. Tudo isso agravado pelo fato de que são os/as professores/as responsabilizados individualmente por seus sucessos e fracassos profissionais, pelas dificuldades e pela qualidade do ensino, bem ao gosto da ideologia liberal vigente.

Ausentes do trabalho de planejamento e de elaboração de projetos, currículos e avaliação, há uma simplificação/empobrecimento da função docente, tornando seu trabalho cada vez mais a mercê da interferência do Estado, que amplia seu uso dos mecanismos persuasivos da sociedade civil, ampliando a hegemonia da classe que representa. (ALVARENGA; VIEIRA; LIMA, 2006, p. 4, grifo nosso).

Desconfigura-se, portanto, o trabalho pedagógico do professor, pois cumprir tarefas não é trabalhar. Ainda, o professor, à mercê do Estado, de suas políticas públicas e da meritocracia, torna-se o único responsável pela qualidade de ensino, recaindo sobre ele a responsabilidade pelo sucesso ou fracasso dos discentes. Esse profis- 
sional não controla seu tempo cumprindo todas essas funções que o Estado lhe atribui. $\mathrm{Na}$ verdade, o tempo do trabalho dos professores não pode ser quantificado e, para que através dele possa haver produção de conhecimento, é necessário que professores se desprendam da lógica capitalista (FERREIRA, 2010).

Por conseguinte, o capitalismo não pode ser visto como uma fatalidade. $\mathrm{O}$ professor tem um potencial emancipatório e de resistência. É por meio do trabalho que esse profissional "ao ser submetido pelo capital ao processo de produção de valor - para a própria valorização desse mesmo capital, e não em benefício dos trabalhadores - contribui para a transformação desta mesma realidade, tendo como horizonte a construção de relações sociais mais justas e igualitárias" (KUENZER, 2004, p. 242). É possível produzir estranhamento dessa realidade. No que tange aos professores, sua qualificação para o trabalho, uma demanda da política pública, faz com que eles, muitas vezes, consigam ter um conhecimento da totalidade de seu trabalho, o que "amplia a possibilidade de participação, de decisão e de controle do próprio trabalho, exigindo trabalhadores de novo tipo, com sólida base de educação geral, a partir da qual se construirá uma formação profissional densa e continuada" (KUENZER, 2004, p. 242). De acordo com Kuenzer, essa

[...] ampliação se dá a partir de uma característica muito peculiar do seu trabalho: a sua natureza não-material, já que não é possível separar o produtor de seu produto. Essa natureza limita, de certo modo, a realização do trabalho segundo o modo capitalista, que passa a se dar indiretamente, por meio de diferentes mediações que "convençam"o trabalhador, pela força ou pela persuasão, a ser artífice da própria exploração e, ao mesmo tempo, buscar sua realização pessoal, enquanto articulado a uma utopia. (KUENZER, 2004, p. 242).

O trabalho, mesmo, muitas vezes, penoso e regulado, está associado à realização profissional. Tal realidade foi identificada nas narrativas dos sujeitos que participaram deste estudo. A produção de conhecimento, em sala de aula, pode ser recompensadora. Isso pode acontecer na medida em que o processo, conhecendo a realidade, busca transformá-la, em suas brechas, promovendo o estranhamento do capital, por meio de sua práxis pedagógica, em que teoria e prática tornam-se uma síntese. Assim, o trabalho, mesmo nesse contexto, adquire sentido, constituindo-se uma prática política e formativa.

\section{Ensino de História: narrativas sobre o seu lugar social}

Qual é o lugar social do Ensino de História na contemporaneidade? Quais os sentidos do trabalho do professor de História? Quais as concepções dos sujeitos de nossa pesquisa sobre isso?

Para Ana, o Ensino de História deve ser:

[...] questionador, fundamentalmente, isso. E isso, pra mim, era claro, muito claro, desde o início, desde antes da formação inicial. Eu queria entender o mundo e a História, pra mim, era o caminho pra entender o mundo. Eu achava bonito ver uma pessoa que estivesse falando algo que a gente via que ela sabia interpretar o que acontecia ao redor. Então, era 
isso que eu queria buscar. Eu queria também interpretar o mundo, também entender o mundo, e era isso que me fazia me aproximar da História, de estudar História.[...]. Eu não dava História pra passar no vestibular, que o vestibular é um concurso, tu estuda pra aquele concurso, tinha que sair daqui com autonomia pra entender a realidade que ele vive ou, pelo menos, saber como buscar mais conbecimento pra entender, uma autonomia intelectual assim. Eu não sei tudo, mas eu mais ou menos sei por onde eu vou começar a procurar, eu vou estudar, vou ler, vou ter uma crítica sobre o contexto. (ANA).

A professora narra que busca, em seu trabalho, ajudar o estudante a entender o mundo. Ela acredita que o Ensino de História nem sempre é importante para os estudantes e que essa importância que o aluno pode atribuir a essa disciplina dependerá da metodologia usada pelo professor enquanto mediador desse processo. $\mathrm{O}$ objetivo de Ana, em sala de aula, não era preparar para o vestibular, e sim desenvolver no estudante uma autonomia intelectual para que ele pudesse tecer críticas sobre o contexto em que vivia.

A professora Roselene, ao ser questionada sobre o lugar social do Ensino de História, pontuou que

[...]é permitir ao aluno elementos para uma formação de uma consciência histórica [...] que permite ligar o passado com o presente [...] nos permite voltar pra trás, olbar pra trás e selecionar no passado aquilo que nos é importante de compreender pra nos posicionar no presente. Já é um lugar comum na História dizer que não existe História do passado, História é sempre História porque é do presente. Bom, mas é a partir dessa percepção, voltar-se para o passado e selecionar do passado o que é importante para que eu possa me posicionar, compreender o presente e a partir dai fazer escolhas para o futuro, eu acho que é esta a função do Ensino de História hoje, especialmente, pra gurizada do ensino médio, aquela gurizada que tá vivendo um momento especial, de pressão muito grande, porque eles estão tendo que fazer escolbas, que vão ser fundamentais pra vida inteira, porque vai resultar num caminho a ser seguido pro resto da vida, uma escolha profissional por exemplo. Então, essa posição, enquanto sujeito, é o que eu chamo de consciência bistórica, a consciência bistórica seria o arcabouço de conbecimento que você teria pra se posicionar no presente enquanto sujeito e fazer escolhas pro futuro.[...] Sem dúvida, muito além do currículo, pra muito além da escola, isso é pra vida. (ROSELENE).

Para Roselene, o Ensino de História deve permitir ao estudante desenvolver o que chama de consciência histórica. Ela explica que essa consciência representa o movimento de selecionar no passado o que é importante para poder se posicionar no presente. Portanto, a consciência histórica seria uma estrutura de conhecimentos usados para pensar o presente, posicionar-se e fazer escolhas para a vida, o que extrapola a educação escolar.

O professor Paulo, no momento em que foi questionado a respeito dos sentidos do estudo da História, explicitou que: 
Eu acho assim, "puxando a brasa pro meu assado", que a História é o mais importante na escola [...] a gente consegue transmitir para os nossos alunos, pelo exemplo, de não aceitar passivamente tudo aquilo que a sociedade te oferece. Então, por isso que eu acho a História muito importante. (PAULO).

O professor Vitor, sobre o sentido do Ensino de História, menciona que:

[...] o Ensino de História tem o papel de formação, essencialmente, política na educação básica, e também é de formação conceitual, teórica e conceitual [...] a História tem que contribuir para que o aluno adquira um vocabulário que vai ajudar ele a entender a sociedade. E esse vocabulário é de todos aqueles conceitos que fazem parte da História, que a gente precisa compreender, como sociedade, cultura, economia, religiosidade, a própria estética em que se estruturam as sociedades, revolução [...] que são conceitos da História que se aprendem através de conteúdos, de circunstâncias do passado, mas que servem pra você entender a sociedade. Então, uma pessoa que não entende esses conceitos muito dificilmente vai conseguir ter uma opinião politica formada,[...] entender a própria política, ela não vai conseguir entender qual é o papel dela na sociedade, no seu emprego, na sua vida pessoal. Então, a História vai muito além de entender fatos, ou então de aprender ou saber esses fatos, você pode até nem saber fato nenhum ou muito pouco sobre História. Mas, se você tiver um dominio desses conceitos fundamentais, que eu acho que essa é a função da História, você vai conseguir entender melhor a dinâmica da sociedade e participar melhor dela. Tem uns que falam, que chamam isso de cidadania ou coisa assim, mas eu acho que eu prefiro dizer que isso é uma alfabetização, do ponto de vista da História é uma alfabetização histórica dos conceitos politicos sociais que te ajudam a entender o mundo. (VITOR).

Conforme o pensamento desse professor, o ensino de História tem um papel de formação política, que só se efetiva por meio da formação conceitual e teórica, que faz o estudante adquirir um vocabulário que lhe ajuda a entender a sociedade, a economia, a religião e a própria estética social. A formação política, para Vitor, vai depender da formação conceitual em História, visto que, se uma pessoa não tem domínio sobre conceitos da História, logo, não vai conseguir entender o contexto em que vive, nem seu lugar na sociedade. Distanciando-se de uma postura factual, Vitor afirma que a História vai além dos fatos e que, se o aluno tiver domínio dos conceitos fundamentais, mesmo que não aprenda sobre os fatos, entenderá melhor a sociedade. Isso ele denomina de alfabetização histórica.

\section{O lugar social do Ensino de História}

Compreendemos que a ciência histórica pode ter um papel orientador, na contemporaneidade, por meio da consciência histórica (RÜSEN, 2001, 2007). Essa consciência, tal como pensada dentro dos cânones das renovadas correntes do pensamento histórico alemão, surge como um dos aportes possíveis e indispensáveis no entendimento da relação entre o universo moral e a conduta ética.

Rüsen tem encarado complexa problemática em função de um projeto audacioso de fazer da análise historiográfica um lugar também propício para a reflexão 
teórica. Numa tradição que tem também Reinhart Koselleck como fonte de inspiração, e um intenso debate com a tradição do clássico historicismo alemão, com a sociologia moderna e com a tradição filosófica alemã, Rüsen lançou-se na tarefa de investigar "a ciência da história como fator da própria história”, ou seja, a ciência da história como objeto de pesquisa e, ao mesmo tempo, como sujeito do pensamento histórico (RÜSEN, 2001, p. 15).

Constrói, portanto, uma fecunda sistematização dos fundamentos da ciência histórica e, ao mesmo tempo, daquilo que a define socialmente enquanto ciência capaz de fornecer orientação às carências do ser humano frente às transformações temporais, tanto individuais quanto estruturais. Tais carências motivam interesses cognitivos para a História. A ciência histórica estuda, com aportes teóricos e epistemológicos, determinados recortes do passado e os conduz de volta ao presente, como narrativa apontada para a vida prática.

Rüsen construiu uma sistematização dos fundamentos da ciência histórica e teve como norte sua capacidade de orientação da práxis humana.

A teoria da história trata do complexo contexto formado pelas carências de orientação pré e para científicas da vida humana prática, pelo modo científico próprio do pensamento histórico e pelas funções de orientação que este exerce. A teoria põe em evidência, pois, que a obtenção de competência profissional não é um processo de aprendizado que abstraia da vida humana concreta e que se refugie numa espécie de torre de marfim científica, mas sim, pelo contrário, que requer a produção de resultados que possuam relevância prática. [...]

A teoria assume, pois, no campo da formação histórica, uma função didática de orientação. [...] torna-se, assim, uma didática, uma teoria do aprendizado histórico; ela transpõe a pretensão de racionalidade que o pensamento histórico em sua cientificidade possui para o enraizamento da história como ciência na vida prática. [...]. (RÜSEN, 2001, p. 41-42, 49).

No pensamento de Rüsen, encontramos uma relação direta entre teoria e Ensino de História, em que "a didática da história caiu nas malhas da teoria da história" (2007, p. 91). Sua ênfase na constituição de sentido comporta a ciência da História relacionada com o presente em que se desenrola e influenciada pelas carências de orientação da práxis humana, e, nesse afã, um lugar promissor para a reflexão didática. Por meio dessa disciplina, é possível analisar recordes do passado, pensando-os a partir de representações da narrativa histórica - transmitida de várias formas: na escola, na mídia, nos livros, na memória coletiva - e reorientá-la de modo a representar vida prática, já que "são as situações genéricas e elementares da vida prática dos homens (experiências e interpretações no tempo) que constituem o que conhecemos como consciência histórica" (2001, p. 54). Para Rüsen, consciência histórica é a "soma das operações mentais com as quais os homens interpretam sua experienciada evolução temporal de seu mundo e de si mesmos de forma tal que possam orientar, intencionalmente, sua vida prática no tempo" (2001, p. 57). Então, é no cotidiano da vida, por intermédio de operações mentais, que pensamos historicamente, pois a consciência 
histórica se constitui, na vida prática, quando narramos e elaboramos representações e, assim, orientamos nosso agir ético e moral (RÜSEN, 2001).

Esse processo permite visualizar a aplicação do conhecimento histórico dos sujeitos como essencial para a formação humana, no momento em que se pensa na vida, através de experiências estéticas e cognitivas, pois:

[...] a consciência histórica não pode ser meramente equacionada como simples conhecimento do passado. A consciência histórica dá estrutura ao conhecimento histórico como um meio de entender o tempo presente e antecipar o futuro. Ela é uma combinação complexa que contém a apreensão do passado regulada pela necessidade de entender o presente e de presumir o futuro. Se os historiadores vierem a perceber a conexão essencial entre as três dimensões do tempo na estrutura da consciência histórica, eles podem evitar o preconceito acadêmico amplamente aceito de que a história lida unicamente com o passado: não há nada a se fazer com os problemas do presente e menos com os do futuro. (SCHMIDT; BARCA; MARTINS, 2011, p. 36-37).

Concluímos que o ser humano atua no mundo não em termos de circunstancialidade, mas a partir de projeções e intencionalidades em sua relação existencial com seu espaço de experiências do presente, passado e futuro, em que "busca atribuir sentido ao que faz ou ao que padece". Isso ocorre no plano intencional: valores, ideias ou interesses fundamentam e orientam o agir. Esse plano antecede, ao menos logicamente, o agir concreto (MARTINS, 2011, p. 49). O ser humano age sob influência das circunstâncias do passado, não sob condições ideais, e projeta o tempo de modo a superar a experiência imediata, constituindo um sentido da experiência no tempo através da narrativa, pois "o homem só pode viver no mundo". Desse modo, ele só consegue relacionar-se com a natureza, com os demais homens e consigo mesmo se não tomar o mundo e a si mesmo como dados puros, mas sim interpretá-los em função das intenções de sua ação e paixão, em que se representa algo que não são, "[...] a consciência histórica é, assim, o modo pelo qual a relação dinâmica entre experiência do tempo e intenção se realiza no processo da vida humana" (RÜSEN, 2001, p. 57-58).

Essa dimensão da consciência histórica humana é essencial na busca por um sentido existencial. Portanto, o pensamento de Rüsen estabelece uma ligação entre a consciência histórica com a didática. Isso acontece quando ele propõe uma reinserção do conhecimento histórico produzido, através da ciência da história, na vida do ser humano, no espaço de vida prática. A consciência histórica é essencialmente humana, é intrínseca à vida, é natural como a ação do homem de modificar a natureza. Então, o trabalho do historiador é só uma das formas de se pensar historicamente, visto que a historicidade é condição do ser humano. De acordo com Rüsen, "consciência histórica é uma categoria geral que não mantém relação com o aprendizado e o ensino de história, mas cobre todas as formas de pensamento histórico; através dela se experiencia o passado e se interpreta-o como história" (RÜSEN, 2006, p. 14) A teoria da consciência histórica diz respeito à cultura histórica, sendo seu conceito básico. Rüsen entende que 
[...] a cultura como um processo integral de vida, de caráter social, que precisa ser compreendida numa perspectiva relacional, com ênfase na interdependência entre todos os aspectos da realidade social e na devida dinâmica da mudança social. Assim, a cultura não se situa como elemento absolutamente superestrutural, nem pode ser entendida como mero reflexo da infraestrutura, mas necessita ser apreendida nos e a partir de processos relacionais. [...] incorpora a cultura numa totalidade, como resultado da condição humana universal, como um conjunto ou produto da experiência humana, como um processo da tradição seletiva e como a ação humana na vida prática. Nesse sentido, entende-se a cultura como algo vivido em um momento e em um lugar; a cultura como produto histórico de um determinado período e sociedade e a cultura como seleção intencional da história da humanidade. Assim, pode-se falar em elementos da cultura referindo-se aos artefatos, ideias, signos e símbolos, às linguagens e tudo que permite e realiza as mediações dos e entre sujeitos, em relações sociais historicamente determinadas, onde estes sujeitos são produtos e também produtores de cultura, constituindo-se enquanto categorias específicas como a cultura histórica e a cultura escolar. (SCHMIDT, 2011, p. 110-111).

Portanto, até mesmo a própria noção do lugar social do Ensino de História se coloca inserida na cultura histórica, e essa, por sua vez, relaciona-se a cultura escolar3. Ainda, na concepção de Rüsen,

[...] da consciência histórica há somente um pequeno passo à cultura histórica. Se examina o papel que tem a consciência histórica na vida de uma sociedade, aparece como uma contribuição cultural fundamentalmente específica que afeta e influi em quase todas as áreas da práxis da vida humana. Assim, a cultura histórica pode ser definida como a articulação prática e operante da consciência histórica na vida de uma sociedade. Como práxis da consciência tem a ver, fundamentalmente, com a subjetividade humana, como uma atividade da consciência, pela qual a subjetividade humana se realiza na prática, cria-se, por assim dizer. [...] A cultura histórica contempla as diferentes estratégias da investigação científico-acadêmica, da criação artística, da luta política pelo poder, da educação escolar e extra-escolar, do ócio e de outros procedimentos da memória histórica pública. (RÜSEN, apud SCHMIDT, 2011, p. 111).

A interpretação da consciência histórica é manifestada na cultura histórica de uma sociedade, que é multidimensional (RÜSEN, 2009, p. 172). O teor da orientação cultural transita entre expressões que envolvem questões identitárias, morais, pedagógicas, políticas, de gênero, de direitos, entre outras perspectivas existenciais, visto que lida com conteúdos da vida humana em sociedade. É nessa cultura que as pessoas constituem sentido histórico para orientar suas vidas. Nesse sentido, a cultura pode ser entendida como a capacidade de aprendizado histórico, visto que, por meio dela, aprendemos a lidar com experiências e a nos orientar. Assim, podemos concluir que o aprendizado histórico não significa puramente aprender conteúdos do passado. É um engajamento do sujeito social que se entende historicamente interpretando a história de forma subjetiva e não apenas no campo objetivo. Logo, uma formação histórica: 


\begin{abstract}
"Formação" [histórica] significa o conjunto das competências de interpretação do mundo e de si próprio, que articula o máximo de orientação do agir com o máximo de autoconhecimento, possibilitando assim o máximo de autorrealização ou de reforço identitário. Trata-se de competências simultaneamente relacionadas ao saber, à práxis e à subjetividade. [...] Formação opõe-se criticamente à unilateralidade, à especialização restritiva e ao afastamento da prática e do sujeito. [...] A categoria da formação refere-se à vinculação entre saber e agir exigida pela carência de orientação do sujeito agente, pois se insere na representação do todo que constitui a situação em que o agente deve lidar com seus problemas. (RÜSEN, 2007, p. 95).
\end{abstract}

A ciência da História só pode ter eficácia a partir do processo de formação histórica, ao adquirir competências fundamentais, que podem ser entendidas a partir da ideia de "competência narrativa da consciência histórica" (RÜSEN, 2007, p. 103). A formação histórica é a articulação entre as formas, os conteúdos científicos e as dimensões do uso prático (RÜSEN, 2007, p. 95). Assim, não é apenas através da pesquisa historiográfica que se realiza essa formação histórica. Isso se dá de outras formas dentro da cultura histórica.

Entendemos, portanto, que o Ensino de História pode ter um papel orientador, estando inserido na cultura histórica. A História que se ensina na escola precisa ser, para o aluno, significativa em termos pessoais. Defendemos as ideias de Rüsen e concordamos com ele quando esse afirma que, grosso modo, aprender história não é puramente aprender sobre o passado. $\mathrm{O}$ sujeito estudante precisa assenhorar-se de si próprio a partir da História, formando sua identidade, sua subjetividade e sua interpretação. Isso implica em questões éticas e morais, além de aspectos existenciais.

\title{
Considerações finais
}

Nas narrativas de nossos sujeitos, foi possível perceber que o trabalho não é visto somente como penoso e regulado, e sim como elemento determinante para a realização profissional. Segundo os relatos deles, a produção de conhecimento, em sala de aula, é uma práxis recompensadora. É através das brechas do sistema que se busca transformar a realidade e o estranhamento da lógica do mercado. $\mathrm{O}$ trabalho do professor é, portanto, político, formativo e humanizador. As condições objetivas do trabalho desse profissional, as lutas por melhores salários e contra várias políticas públicas opressoras dos direitos do professor, são evocadas nas falas deles, mas isso não separa o trabalho da perspectiva de felicidade e da vida do professor, nem o distanciam da práxis; ao contrário, o trabalho, por eles, é visto como cheio de sentidos e significados.

Essa noção se relaciona com as atribuições do lugar social do Ensino de História, o qual é visto como tendo um lugar de questionamento da sociedade, de formação de consciência histórica e de formação política. Os professores de História, em sua grande maioria, pela própria particularidade da disciplina, desenvolvem um engajamento relativo a muitas questões e compreendem o Ensino de História como um lugar essencialmente crítico, contestador e emancipador para o estudante. 


\section{Referências}

ALVARENGA, E.; VIEIRA, E.; LIMA, M. M. Os impactos das políticas educacionais brasileiras no trabalho docente. In: Anais do VI Seminário da Rede Lation-americana de Estudos sobre Trabalho Docente - Rede ESTRADO. Rio de Janeiro, nov. 2006.

DELORY-MOMBERGER, C. Biografia e educação: figuras do indivíduo-projeto. Natal: EDUFRN, São Paulo: PAULUS, 2008.

. Os desafios da pesquisa biográfica em educação. In: SOUZA, E. C. (Org.). Memória, (auto)biografia e diversidade: questões de método e trabalho docente. Salvador: EDUFBA, 2011.

ENGUITA, M. A ambigüidade da docência: Entre o profissionalismo e a proletarização. Teoria e Educação n. 4. Porto Alegre, 1991.

ESTEVE, J. M. O mal-estar docente: a sala de aula e a saúde dos professores. São Paulo: EDUSC, 1999.

FERREIRA, L. S. O trabalho dos professores na escola: quando o tempo se trai. In: Revista HISTEDBR Online. Campinas: 2010, p. 206-222.

JOSSO, M.-C. Experiências de vida e formação. Lisboa: EDUCA, 2002.

. Os relatos de histórias de vida como desvelamento dos desafios existenciais da formação e do conhecimento: destinos sócio-culturais e projetos de vida programados na invenção de si. In: ABRAHÃO, M. H. M. B.; SOUZA, E. C.(Org.). Tempos, narrativas e ficções: a invenção de si. Porto Alegre: EDIPUCRS, 2006.

KUENZER, A. Z. Sob a reestruturação produtiva, enfermeiros, professores e montadores de automóveis se encontram no sofrimento do trabalho. Trabalho, Educação e Saúde. Rio de Janeiro, v. 2, n. 1, p. 239-265, 2004.

MARTINS, E. R. Educação e Consciência Histórica. In: SCHMIDT, M. A.; CAINELLI, M. Educação Histórica: Teoria e Pesquisa. Ijuí: Ed. Unijuí, 2011.

RICOEUR, P. A identidade narrativa e o problema da identidade pessoal. Trad. Carlos João Correia. Arquipélago, n.7, p. 177-194, 2000. Disponível em: <http://metafisica.no.sapo.pt/ricoeur.html>. Acesso em: 4 ago. 2012.

RÜSEN, J. A Razão Histórica: teoria da história: os fundamentos da ciência histórica. Brasília: $\mathrm{UnB}, 2001$.

Didática da História: Passado, Presente e Perspectivas a Partir do caso Alemão. Práxis Educativa. Ponta Grossa, PR. v. 1, n. 2, 16, jul.-dez. 2006.

Como dar sentido ao passado: questões relevantes de meta-história. História da Historiografia, n. 2, mar., 2009.

SAVIANI, D. Trabalho e educação: fundamentos ontológicos e históricos. Revista Brasileira de Educação, ANPEd. Rio de Janeiro: 2007, p.152-165.

SCHMIDT, M. A.; BARCA, I.; MARTINS, E. R. (Orgs.). Jörn Rüsen e o Ensino de História. Curitiba: Ed. UFPR, 2011.

\section{Notas}

\footnotetext{
${ }^{1}$ Esteve, em sua obra "O mal-estar docente: a sala de aula e a saúde dos professores", classifica os fatores que geram mal estar entre os de primeira e segunda ordem. Segundo Esteve, "Fatores primários, referindo-se aos que incidem diretamente sobre a ação do professor em sala de aula, gerando tensões associadas a sentimentos e emoções negativas; e, por outro lado, fatores secundários, referentes às condições ambientais, ao
} 
contexto em que se exerce a docência. A ação desse segundo grupo de fatores é indireta, afetando a eficácia docente ao promover uma diminuição da motivação do professor no trabalho, de sua implicação e seu esforço. Isolados, têm apenas significado intrínseco, mas, quando se acumulam, influem fundamentalmente sobre a imagem que o professor tem de si mesmo e de seu trabalho profissional, gerando uma crise de identidade que pode chegar, inclusive à autodepreciação do ego" (1999, p. 27).

${ }^{2}$ Conforme Ferreira (2010, p. 2007), o emprego é diferente do trabalho: "O emprego diz respeito à capacidade dos seres humanos de manterem-se, de poderem consumir".

${ }^{3}$ Ver nota 31, em que explicamos o conceito de cultura escolar com base em Forquin (1993).

* Professor doutor da Universidade Federal de Santa Maria, Santa Maria, Rio Grande do Sul, Brasil.

** Professora da rede pública estadual do Rio Grande do Sul, Santa Maria, Rio Grande do Sul, Brasil.

\section{Correspondência}

Jorge Luiz da Cunha - Universidade Federal de Santa Maria, Centro de Educação. Campus Universitário, Camobi, CEP: 97105-900 - Santa Maria, Rio Grande do Sul - Brasil.

E-mail: jlcunha11@yahoo.com.br - lis_cardozo@hotmail.com

Recebido em 08 de julho de 2015

Aprovado em 11 de agosto de 2015 